\title{
Exotic congenital scoliosis - the effects of early arthrodesis
}

\author{
Scolioza congenitală exotică - efectele artrodezei precoce
}

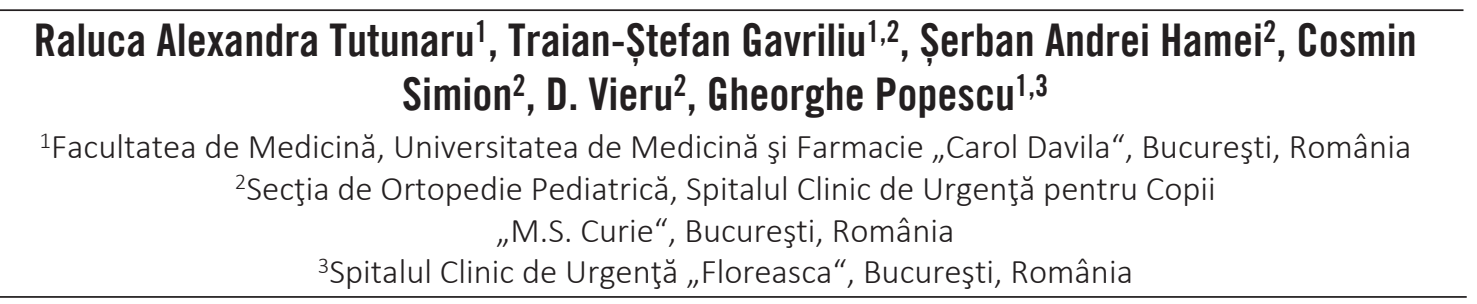

ABSTRACT
Aim. The article presents the difficulties encountered in the treatment of exotic scoliosis and the
optimal treatment options for this pathology.
Material and method. The case presentation of an exotic scoliosis with T6-T11 vertebral block with
hemiver-tebrae, rib fusions and rib agenesis on the concave side, L1-T12 butterfly vertebrae, L2
hemivertebra and lumbar rachischizis, associated with a diastematomyelic bony spur at T12-L1 level,
previous operated, re-quiring surgical reintervention.
Results. Surgical decisions not optimized for each patient may lead to worsening of evolution and raise
dif-ficulties in later treatment.
Discussions. The resection of the hemivertebra and spinal fusion limited to 2 levels is the optimal
treatment for congenital scoliosis that corrects the scoliosis curve and stops progression. The VEPTR
device is the most effective choice to ensure pulmonary development compatible with life in patients with
thoracic insuffi-ciency syndrome.
Conclusions. Exotic scoliosis is a challenging pathology that requires prognosis of development in order to
be able to choose the optimal treatment to ensure the growth and development of the thoracic cavity,
the pulmonary system and the spinal cords.

Keywords: exotic scoliosis, hemivertebrae, diastematomyelia, VEPTR

\section{REZUMAT}

Obiective. Articolul prezintă dificultăţile întâlnite în cadrul tratamentului scoliozelor exotice şi variantele optime de tratament al acestei patologii.

Material şi metodă. Prezentarea unui caz de scolioză exotică cu bloc vertebral cu hemivertebre la nivel T6-T11, fuziuni şi agenezii costale pe partea concavă, vertebre în fluture la nivel L1-T12, hemivertebră la nivel L2 şi rahischizis lombar ce asocia şi o lamă osoasă diastematomielică la nivel T12-L1 operată, ce a necesitat reintervenţia chirurgicală.

Rezultate. Deciziile chirurgicale neoptimizate fiecărei patologii în parte pot duce la agravarea evoluţiei şi ridică dificultăţi în tratamentul ulterior.

Discuţii. Rezecţia hemivertebrei şi fuziunea spinală limitată la 2 nivele este varianta optimă de tratament a scoliozelor congenitale ce poate asigura redresarea curburii scoliotice şi oprirea progresiei acesteia. Dispozitivul VEPTR este varianta cea mai eficientă de asigurare a unei dezvoltări pulmonare compatibile cu viaţa în cadrul sindromului de insuficienţă toracică.

Concluzii. Scoliozele exotice reprezintă o patologie provocatoare ce necesită previziune a dezvoltării pentru a putea alege un tratament optim, ce să asigure creşterea şi dezvoltarea atât a cavităţii toracice şi a pulmonului cât şi a coloanei vertebrale.

Cuvinte cheie: scolioză exotică, hemivertebră, diastematomielie, VEPTR

\section{OBIECTIVE}

Scolioza exotică reprezintă scolioza cu debut precoce cu o diformitate complexă, ce asociază multiple defecte, de obicei mixte, de formare şi de segmentare, care este de regulă asociată unor deformări primare a cavității toracice ce duc la sindromul de insuficiență toracică $(1,2)$. 
Hemivertebra reprezintă cea mai frecventă malformație de formare prezentă în cazul scoliozelor congenitale. Hemivertebra segmentată are un potențial evolutiv crescut, motiv pentru care rezecția sa şi fuziunea limitată a segmentului supra şi subiacent trebuie realizate la vârste cât mai mici, începând chiar cu vârsta de 1 an. Cu cât vârsta pacientului este mai mare, cu atât rezultatele intervenției sunt mai imprevizibile, iar nivelul segmentului ce necesită fuziune creşte (3). Corecția obținută atât postoperator, cât şi pe termen lung este cu atât mai bună cu cât intervenția chirurgicală este efectuată la vârste mai mici, înainte de apariția modificărilor structurale şi a curburilor secundare (4).

Asocierea dintre hemivertebră şi diastematomielie este rar întâlnită în populație; doar 1,8-16\% dintre scoliozele congenitale asociază lamă diastematomielică (5). În literatura de specialitate există numeroase dezbateri privind indicația exciziei lamei diastematomielice în absența manifestărilor neurologice chiar în prezența unei curburi scoliotice ce necesită tratament chirurgical. Simpla excizie a hemivertebrei şi fuziunea segmentară scurtează practic coloana şi nu reprezintă o indicaţie clară pentru excizia lamei diastematomielice, însă orice alt procedeu de îndreptare a curburilor secundare poate duce la elongație medulară care este fixată în jurul lamei şi, în consecință, la leziuni medulare secundare, ceea ce reprezintă o indicație pentru rezecția lamei diastematomielice în absența manifestărilor neurologice (6). O altă discuție este legată de ritmul de creştere diferit al structurilor osoase vertebrale față de cel al elementelor nervoase ce poate cauza manifestări neurologice o dată cu creşterea (7).

Fuziunea spinală bisegmentară bilaterală precoce a coloanei toracale este considerată metoda de elecție în tratamentul scoliozelor congenitale având un efect neglijabil asupra creşterii coloanei vertebrale. În cazul scoliozelor congenitale exotice ce asociază şi fuziuni spinale, există studii care arată că prin simpla fuziune spinală segmentară poate rezulta o coloană toracală scurtă care poate duce la apariția sindromului de insuficiență toracică (8).

Sindromul de insuficiență toracică presupune incapacitatea toracelui de a suporta creşterea normală pulmonară şi funcția respiratorie normală (9). Creşterea în volum a toracelui are loc pe parcursul copilăriei continuând în adolescență, însă numărul alveolelor nu creşte decât până la 4 ani, motiv pentru care toracostomiile de expansiune şi montarea unui dispozitiv VEPTR trebuie realizate cât mai precoce, ideal la vârsta de 1 an (10).
Dispozitivul VEPTR asigură mărirea cavității toracice prin distractări progresive asigurând indirect şi controlul diformității spinale $(9,11)$.

Obiectivul principal al acestui articol este de a prezenta cazul unei paciente la care nu s-au urmat principiile de tratament privind momentul operator şi tehnica operatorie.

\section{MATERIALE ŞI METODĂ}

Vom prezenta cazul unei paciente în vârsta de 6 ani, cu o scolioză exotică, operată, ce prezintă actualmente un important dezechilibru postural şi o marcantă disproporție între înălțimea trunchiului şi lungimea membrelor (Fig. 1). Aceasta prezintă dispariţia lordozei lombare, antepulsia bazinului şi a trunchiului, apariția unei cifoze joncționale, accentuarea lordozei cervicale şi o uşoară poziție în genu flexum pentru a permite menținerea echilibrului în ortostatism. Înaintea intervenției chirurgicale de la vârsta de 4 ani, pacienta prezenta o scolioză congenitală de tip exotic ce prezenta următoarele malformații vertebrale: bloc vertebral cu hemivertebre la nivel T6-T11, fuziuni şi agenezii costale pe partea concavă, vertebre în fluture la nivel L1-T12, hemivertebră la nivel L2 şi rahischizis lombar (Fig. 2 A şi B). De asemenea, s-a identificat şi o lamă osoasă diastematomielică la nivel T12-L1 (Fig. 2 C şi D).

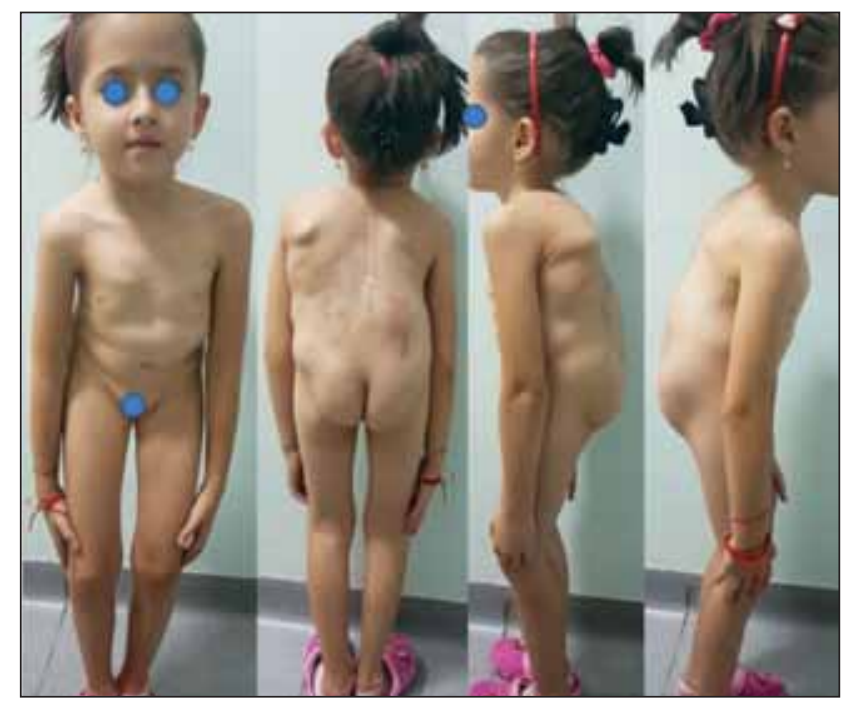

FIGURA 1. Aspectul clinic la 6 ani, înainte de reintervenția chirurgicală; se observă disproporția dintre torace şi membre, cu o atitudine de genu flexum, antepulsia trunchiului şi a toracelui cu dispariția lordozei lombare

Intervenția chirurgicală a presupus excizia lamei diastematomielice, rezecția posterioară a blocului hemivertebral T9-L2 şi implant VEPTR lamină vertebrală-aripă iliacă bilateral. Au urmat apoi, la 
FIGURA 2. A şi B - Imagine de reconstrucție 3D a rahisului față şi spate, preoperator, la vârsta de 4 ani; C - Secțiune transversală CT a lamei de diastematomielie;

$D$ - Secțiune transersală IRM a lamei de diastematomielie;

E- Sectiune transversală CT a lamei diastematomielice la vârsta de 6 ani

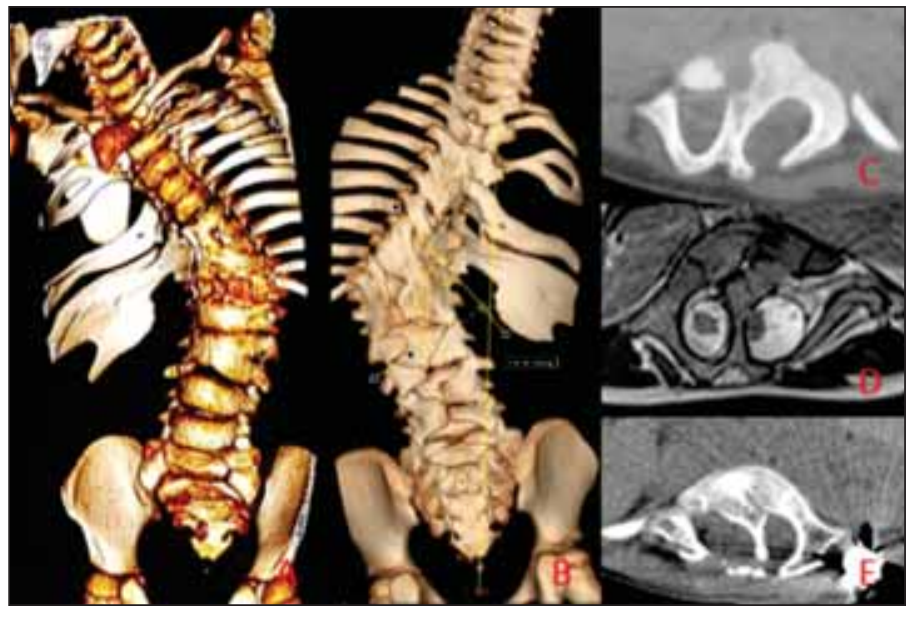

intervale de 7 luni, 2 distractări ale dispozitivului VEPTR de pe partea dreaptă cu $1 \mathrm{~cm}$, respectiv 0,5 $\mathrm{cm}$ şi extragerea clemei proximale de prindere a sleevului dispozitivului VEPTR de pe partea stângă.

Predictiv, în cursul unei dezvoltări normale, pe parcursul unui an şi jumătate, conform schemelor de creştere ale lui Dimeglio şi Bonnel cu privire la creşterea coloanei vertebrale, pacienta trebuia să prezinte o creştere în înălțime a coloanei vertebrale de $\sim 2 \mathrm{~cm}(10)$. Evoluția reală, pe parcursul acestui an şi jumătate, ne arată în schimb stagnarea creşterii coloanei vertebrale sub implant $(10,29 \mathrm{~cm}$ preo- perator T1-T12 vs. $10,48 \mathrm{~cm}$ la 1 an şi jumătate), accentuarea curburii scoliotice $(57,4$ grade Cobb preoperator vs 63,3 grade Cobb la 1 an şi jumătate) şi o aparentă echilibrare a umerilor cu o discrepanță de nivel a umerilor ameliorată de la $3,71 \mathrm{~cm}$ la 1,9 cm (Fig. 3 A şi B). În plan sagital însă, se observă dispariția completă a lordozei lombare şi apariția unei cifoze toracale joncționale (prăbuşirea anterioară a toracelui superior) cu apariția unei hiperlordoze cervicale secundare (Fig. 3 D şi E). Sindromul de insuficiență toracală a rămas prezent cu accentuarea respirației de tip abdominal.
FIGURA 3. Imagine radiologică față şi profil, evolutiv, preoperator la 4 ani (A şi D), cu cele 2 dispozitive VEPTR montate la 4 ani (B şi E) şi postoperator după rezecția lamei de diastematomielie şi repoziționarea VEPTR-ului (C şi F)

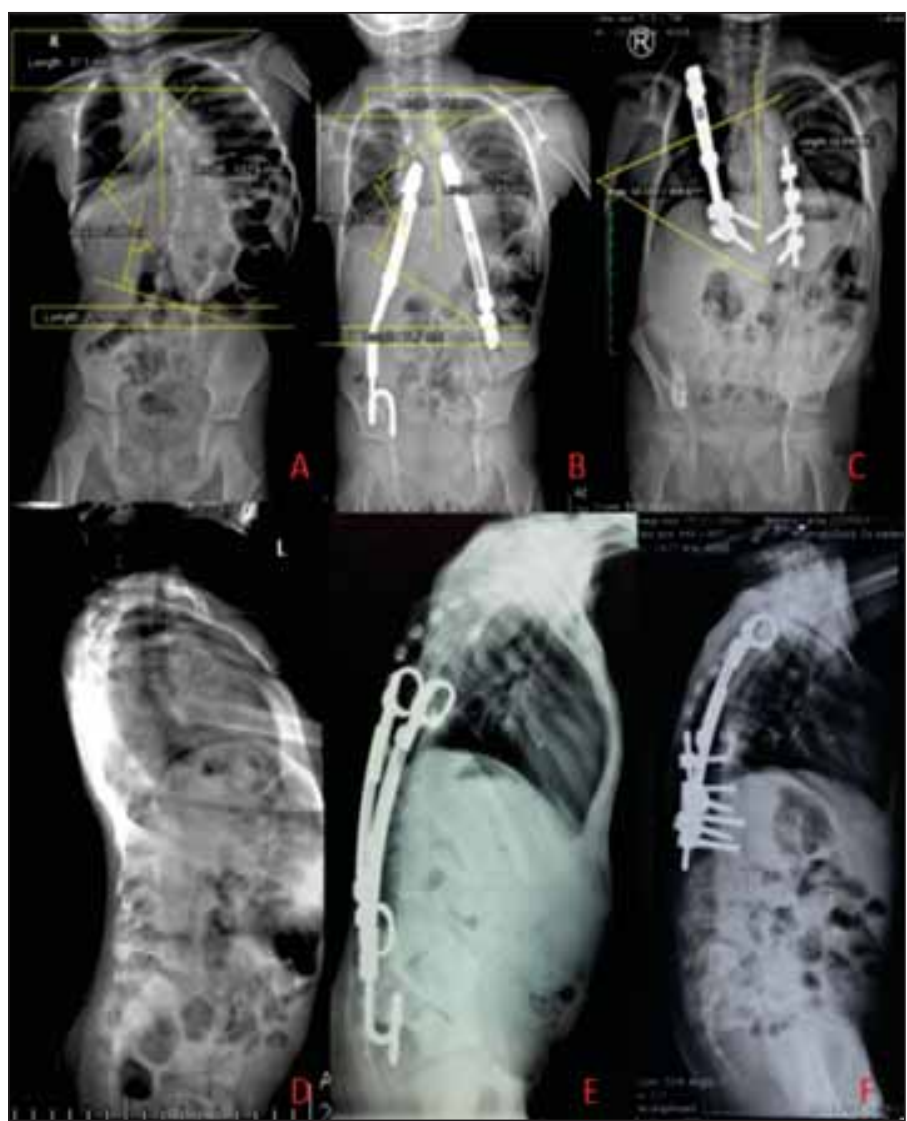


La vârsta de 6 ani, se decide reintervenția chirurgicală ce presupune iniţial suprimarea dispozitivului VEPTR de pe convexitate şi repoziţionarea componentei distale a dispozitivului VEPTR stâng, de pe bazin pe L5 pentru a elibera joncțiunea lombosacrată şi a putea efectua investigații ulterioare cu minime artefacte, în vederea reevaluării mozaicului de malformații congenitale prezente. Intraoperator, s-a constatat rigidizarea coloanei sub implanturi realizate pe o distanță mult prea extinsă şi bilateral. De asemenea, s-a constatat o osteoporoză marcantă a corpilor vertebrali. Examenul computer tomograf al statusului actual ne relevă prezența în continuare a lamei diastematomielice (Fig. 2 E), a unui bloc vertebral de la T3-L2 şi menţinerea fuziunilor costale sub forma unei platoşe costale, precum şi prezența unei zone de fuziune induse de grefarea cu rol de fuziune in situ a zonei de maximă curbură scoliotică.

\section{REZULTATE}

S-a decis reintervenția chirugicală pentru excizia completă a lamei diastematomielice (pentru a evita eventualele complicații neurologice ce pot rezulta în urma procedeelor ortopedice) cu repoziţionarea VEPTRului CIII-L1, efectuarea a 3 toracostome, rezectie hemivertebră T11 de pe convexitate şi fuziune segmentală unilaterală T8-T10T12-L1 (Fig. 4 B).

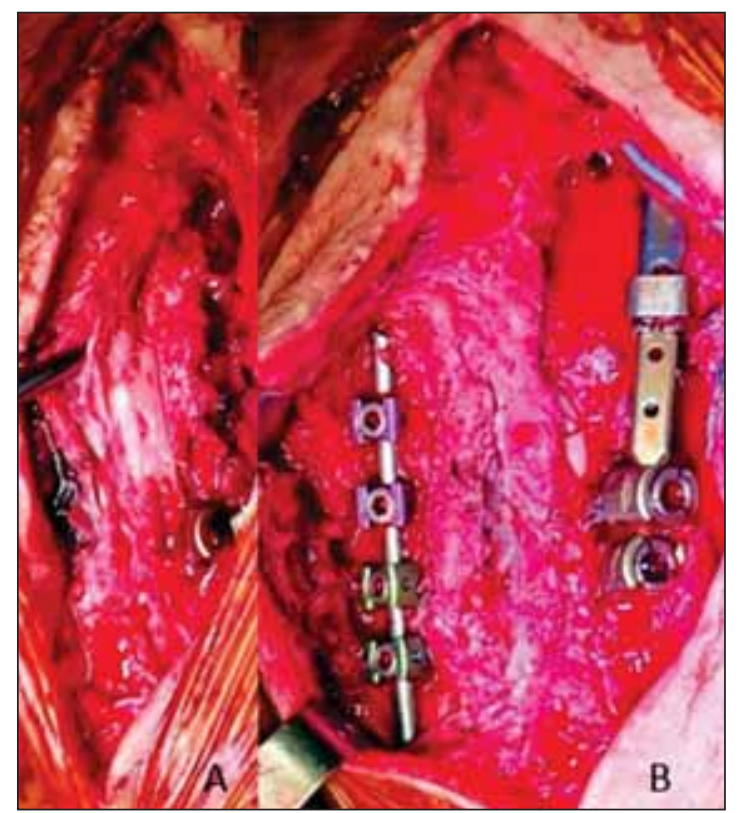

FIGURA 4. Aspectul intraoperator

Obiectivele acestei intervenții sunt corecția parțială a curburii scoliotice prin rezecția hemivertebrei şi fuziunea segmentară unilaterală pe 4 nive- luri precum şi asigurarea stabilității montajului prin plasarea corectă contralaterală a dispozitivului VEPTR. Raționamentul intervenției a fost de a corecta curbura scoliotică şi de a opri evoluția, dar şi de a încerca expandarea cavității toracice şi distractarea în lungime a coloanei toracale cu ajutorul dispozitivului VEPTR. Intraoperator, s-a constat o importantă fibroză locală atât la nivelul regiunii toracale joase, cât şi a regiunii lombare, cu prezența unor zone de artrodeză completă (Fig. 4 A). Postoperator, s-a observat o uşoară corectare a curburii scoliotice, ajungând la 50 grade (Fig. 3 C). Urmează a se face distractări seriate la fiecare 4 luni pentru ca la terminarea creşterii să se convertească montajul în vederea corecției definitive a diformității spinale restante. Evoluția cazului este impredictibilă pe termen lung.

\section{DISCUŢII}

Progresia naturală a scoliozelor congenitale exotice, cu fuziuni costale, bară unilaterală şi hemivertebre este de 5-10 grade anual, adică o agravare de minim 120 de grade până la finalul creşterii, ceea ce poate duce la decesul prematur al pacientului prin insuficiență cardiorespiratorie; motiv pentru care sistarea evoluției curburii scoliotice este obiectivul principal şi trebuie realizată cât mai rapid. În literatură este prezentat cazul unui pacient cu o scolioză congenitală de 90 de grade cu o bară unilaterală nesegmentată T6-T9, hemivertebre T9 şi T12 pe partea contralaterală şi fuziuni costale C7-C12 pe partea concavă, ce a fost tratat prin fuziune spinală posterioară T3-T12 şi osteotomii ale coastelor fuzionate la vârsta de 1 an. Reevaluarea la 36 de ani distanță a arătat o scădere a capacității funcționale pulmonare la $42 \%$ față de normal, dar cu stagnarea progresiei curburii scoliotice la valorile postoperatorii (12).

Obținerea unei lungimi a coloanei toracale de minimum $18 \mathrm{~cm}$ conferă o funcție pulmonară acceptabilă ce scade mortalitatea (13), astfel, momentul intervenției şi nivelul fuziunii trebuie alese ținând cont de aceste două aspecte: înălțimea coloanei vertebrale şi gradul curburii scoliotice.

Rolul principal al dispozitivului VEPTR este de a îmbunătăţi funcția pulmonară prin stabilizarea şi distractarea toracelui şi secundar de a controla curbura scoliotică. Indicațiile acestui dispozitiv sunt bine stabilite în cadrul FDA-ului (United States Food and Drug Administration): sindromul de coaste flotante, sindromul constrictiv toracic (include scolioză şi fuziuni costale), sindromul de torace hipoplastic (include sindromul Jeune, acon- 
droplazia, sindromul Jarcho-Levin, sindromul Ellis van Creveld) şi scoliozele congenitale sau neurologice progresive. Absența creşterii coloanei şi evoluția curburii scoliotice sub acest dispozitiv pot fi semne de indicație terapeutică inadecvată sau eroare tehnică de aplicare.

\section{CONCLUZII}

Scoliozele exotice reprezintă o patologie complexă prezentând manifestări clinice şi impact asupra dezvoltării încă de la vârste foarte mici. Tratamentul acestei patologii este o adevărată provocare în ceea ce priveşte nu numai rezolvarea problemei cauzatoare de curbura scoliotică, dar şi asigurarea unei creşteri cât mai aproape de normal a cavității toracale şi a coloanei vertebrale prin evitarea fuziunii spinale pe segment lung. Orice manevră chirurgicală de corecție efectuată direct asupra unei coloane aflate în creştere trebuie analizată şi pusă în balanţă cu efectele şi repercusiunile sale pe termen lung. Artrodezele segmentare limitate ale unei coloane vertebrale aflate în creştere sunt necesare atât timp cât ele aduc corectarea şi, mai ales, sistarea evoluției curburii scoliotice.

Conflict of interest: none declared Financial support: none declared

\section{BIBLIOGRAFIE}

1. Campbell R.M. Spine deformities in rare congenital syndromes: Clinical issues. Spine. 2009; http://doi.org/10.1097/ BRS.0b013e3181ab64e9;

2. Campbell R.M., Smith M.D. Thoracic insufficiency syndrome and exotic scoliosis. In Journal of Bone and Joint Surgery - Series A, 2007, Vol. 89, pp. 108-122,. https://doi.org/10.2106/JBJS.F.00270;

3. Zhu X., Wei X., Chen J. et al. Posterior hemivertebra resection and monosegmental fusion in the treatment of congenital scoliosis. Annals of the Royal College of Surgeons of England, 2014, 96(1), 41-44. https://doi.org/10.1308/003588414X13824511650173;

4. Chang D.-G., Suk S.-I., Kim J.-H. et al. Surgical outcomes by age at the time of surgery in the treatment of congenital scoliosis in children under age 10 years. The Spine Journal: Official Journal of the North American Spine Society, 2015, 15(8), 1783-1795. https://doi. org/10.1016/j.spinee.2015.04.009;

5. Uzumcugil A., Cil A., Yazici M. et al. The efficacy of convex hemiepiphysiodesis in patients with iatrogenic posterior element deficiency resulting from diastematomyelia excision. Spine, 2003, 28(8), 799-805. https://doi.org/10.1097/00007632-200304150-00013;

6. Leung Y.L. Combined diastematomyelia and hemivertebra: A REVIEW OF THE MANAGEMENT AT A SINGLE CENTRE. Journal of Bone and Joint Surgery - British Volume, 2005, 87-B (10), 13801384. https://doi.org/10.1302/0301-620X.87B10.16050;

7. Gavriliu S., Vlad C., Georgescu I., Burnei G. Diastematomyelia in congenital scoliosis: A report of two cases. European Spine Journal, 23(SUPPL.2), 2014, https://doi.org/10.1007/s00586-014-3218-x;

8. Banagan K.E. Sponseller P. D. Surgical treatment of congenital scoliosis. Current Opinion in Orthopaedics. 2007, https://doi. org/10.1097/BCO.0b013e32810c8d38;

9. The Vertical Expandable Prosthetic Titanium Rib in the treatment of spinal deformity due to progressive early onset scoliosis; Norman Ramireza,c, John M. Flynna, Jose Anibal Serranoc, Simon Carlob,c and Alberto S. Cornierb, c, Journal of Pediatric Orthopaedics B 2009, Vol. 18, No. 4;

10. Emans J.B., Caubet J.F., Ordonez C.L. et al. The Treatment of Spine and Chest Wall Deformities with Fused Ribs by Expansion Thoracostomy and Insertion of Vertical Expandable Prosthetic Titanium Rib. Spine, 30 (Supplement), 2005, S58-S68. https://doi. org/10.1097/01.brs.0000175194.31986.2f;

11. Campbell R.M., Adcox B.M., Smith M.D. et al. The effect of mid-thoracic VEPTR opening wedge thoracostomy on cervical tilt associated with congenital thoracic scoliosis in patients with thoracic insufficiency syndrome. Spine, 2007, 32(20), 2171-2177. https://doi. org/10.1097/BRS.0b013e31814b2d6c;

12. Winter R.B., Lonstein J.E. Congenital thoracic scoliosis with unilateral unsegmented bar and concave fused ribs: Rib osteotomy and posterior fusion at 1 year old, anterior and posterior fusion at 5 years old with a 36-year follow-up. Spine, 2007, 32(26). https://doi. org/10.1097/BRS.0b013e31815ce6f4;

13. Tis J.E., Karlin L.I., Akbarnia B. Early onset scoliosis: modern treatment and results. Journal of Pediatric Orthopedics, 2012, 32(7), 647-57. https://doi.org/10.1097/BPO.0b013e3182694f18; 